\title{
Understanding Victim Cooperation in Cases of Nonfatal Gun Assaults $†$
}

A manuscript submitted to the Criminal Justice and Behavior

\author{
Natalie Kroovand Hipple* \\ Indiana University \\ Department of Criminal Justice \\ 1033 East Third Street \\ 309 Sycamore Hall \\ Bloomington, IN 47405 \\ 812.856 .2759 (o) \\ nkroovan@indiana.edu (e) \\ ORCID 0000-0003-3924-75980 \\ Kristina Thompson Garrity \\ University of Missouri - St. Louis \\ Department of Criminology and Criminal Justice \\ 533 Lucas Hall \\ St. Louis, MO 63121 \\ kjtbqb@mail.umsl.edu (e) \\ Beth M. Huebner \\ University of Missouri - St. Louis \\ Department of Criminology and Criminal Justice \\ 533 Lucas Hall \\ St. Louis, MO 63121 \\ huebnerb@umsl.edu (e) \\ Lauren A. Magee \\ Indiana University School of Medicine \\ Department of Pediatrics, Children's Health Services Research \\ 410 W. $10^{\text {th }}$ Street \\ Indianapolis, IN 46202 \\ lamagee@iu.edu (e)
}

March 2019

\begin{abstract}
*Corresponding author
$\dagger$ This project was supported by Award No. 2013-R2-CX-0015, awarded by the National Institute of Justice, Office of Justice Programs, U.S. Department of Justice. The opinions, findings, and conclusions or recommendations expressed in this publication are those of the author(s) and do not necessarily reflect those of the Department of Justice.
\end{abstract}

This is the author's manuscript of the article published in final edited form as:

Magee, N. K. H., Kristina J. Thompson, Beth M. Huebner, Lauren A. (2019). Understanding Victim Cooperation in Cases of

Nonfatal Gun Assaults—Natalie Kroovand Hipple, Kristina J. Thompson, Beth M. Huebner, Lauren A. Magee, 2019. Criminal Justice and Behavior. https://doi.org/10.1177/0093854819848806 


\section{Author bios:}

Natalie Kroovand Hipple is an Associate Professor in the Department of Criminal Justice at Indiana University. Her research interests include gun violence, police partnerships and problem solving, police line of duty deaths and restorative justice. Her current work focuses nonfatal shootings and crime reduction strategy implementation.

Kristina Thompson Garrity is a doctoral candidate in the Department of Criminology and Criminal Justice at the University of Missouri - St. Louis. Her research interests include exploring spatial and temporal dimensions of structure and violence, social control theories of crime and deviance, and the practical consequences of legal responses to rule breaking.

Beth M. Huebner is a professor and Presidential Engagement Fellow in the Department of Criminology and Criminal Justice at the University of Missouri - St. Louis. Her principal research interests include the collateral consequences of incarceration, racial and gender disparities in the criminal justice system, and public policy. She is currently serving as the research partner for the St. Louis Police-Prosecution Partnership (3PI) Initiative.

Lauren A. Magee is a post-doctoral research fellow at the Indiana University School of Medicine Her research focuses on the intersection of criminal justice and public health to examine how community mechanisms and social determinants of health are associated with violent victimization. 


\begin{abstract}
Victims play a central role in criminal case processing, but research suggests many victims do not report crimes to police or cooperate in a police investigation. This study extends the literature on victim cooperation by examining the effect of incident level variables and neighborhood characteristics on victim cooperation in nonfatal shooting incidents. The sample includes 1,054 nonfatal shooting victims from two Midwestern cities. Results using binary logistic regression suggest that incident and victim characteristics are significantly associated with cooperation, but race conditions the effect of injury severity and motive on cooperation. The willingness to cooperate among whites is contingent on injury severity while nonwhite victims do not become markedly more cooperative when confronted with serious injury. Race also moderates the relationship between crime motive and cooperation. This work demonstrates the need to incorporate nonfatal firearm violence into studies of victim cooperation and gun crime more broadly.
\end{abstract}

\title{
Keywords:
}

Gun violence

Nonfatal shooting

Victim cooperation

Rational choice 


\section{Introduction}

Scholars have argued that in most criminal cases, the victim is the gatekeeper to the criminal justice system (Gottfredson \& Gottfredson, 1988). Victims play integral roles in the investigation, clearance, and prosecution of crimes, as well as, the sentencing of defendants (Erez \& Tontodonato, 1990; Goodman, Bennett, \& Dutton, 1999; Kaiser, O’Neal, \& Spohn, 2017; O’Neal, 2017). The efficacy of the criminal justice system can be contingent on the decisions victims make to summon law enforcement and cooperate with criminal investigations. Still, recent reports indicate that less than half of crimes are reported to law enforcement (Truman \& Morgan, 2016).

Given the centrality of victims to the criminal justice process, it is not surprising that scholars have worked to identify the factors that predict crime reporting (Fisher, Daigle, Cullen, \& Turner, 2003). Much of the literature has characterized victim decision-making as an intentional weighing of the costs and benefits associated with invoking law enforcement (Block, 1974; Kaiser et al., 2017; Xie \& Lauritsen, 2012). Research suggests that individuals often are reluctant to call on police because they do not trust the response. This lack of trust in the police is often heightened in poor communities and among men of color, where police practices can compromise police legitimacy and contribute to legal cynicism (Clampet-Lundquist, Carr, \& Kefalas, 2015; Gau \& Brunson, 2010).

At the same time, mandatory reporting laws can supersede the decision by a victim to report a crime. For instance, forty-one states have laws requiring health care facilities or physicians to report gunshot wound injuries to local law enforcement (Gupta, 2007). After medical professionals have reported a crime to the police, victims must choose whether to cooperate with the police investigation. Research on sexual assault and intimate partner violence 
suggests that victim cooperation may be an essential factor in the decision to arrest and charge offenders (Dawson \& Dinovitzer, 2001; O’Neal \& Spohn, 2017; O’Neal, Tellis, \& Spohn, 2015).

The goal of this study is to document the prevalence and predictors of victim cooperation in the investigation of nonfatal shooting incidents in two Midwest cities. Data for this study are culled from official police records and include information on victim and offense characteristics and neighborhood indicators of poverty and race. This work is unique in two primary ways. First, research to date has largely examined the decision to report a crime, but the role of a victim does not terminate at the reporting stage. The police, who are often not at the scene when a crime occurs, require information from victims with the goal of offender apprehension and eventual prosecution. Extant research on victim cooperation with police investigations has centered on sexual assault (Kaiser et al., 2017), but little is known about victim cooperation in gun crime incidents.

Second, this study adds to the existing research on gun crime. Gun violence is a widespread, consistent, and costly public health issue in the United States (Wintemute, 2015). Survival rates for gun injuries have increased over the past decade (Kalesan et al., 2017). Nonfatal shootings also present a unique analytic case and include aggravated assaults where a penetrating physical injury from a firearm is present. To date most research on gun crimes have focused on homicide, but existing research suggests nonfatal shootings occur at least four times more often than gun homicides (Hipple \& Magee, 2017). In addition, gun assaults engender a fear of retaliation that is largely unique to this crime type, making victim cooperation essential to solving cases (Papachristos, 2009). Overall, this study has potential to inform work on victimology and larger policy discussions of gun crime in the United States. 


\section{Victim Cooperation}

Individual Perspectives

Victim cooperation with police and police-community interactions more broadly are influenced by individual and community factors. Many studies have adopted a rational choice perspective to explain individual-level decisions to report crimes or cooperate with police investigations (Felson, Messner, Hoskin, \& Deane, 2002; Galvin \& Safer-Lichtenstein, 2018; Kaiser et al., 2017; O’Neal, 2017). The most parsimonious version of this theory proposes that individuals simply pursue goals in ways that maximize pleasure (benefits) and minimize pain (costs) (Block, 1974; Kaiser et al., 2017; Xie \& Lauritsen, 2012). This articulation suggests that cooperation is likely when two interrelated conditions are satisfied. First, it is necessary for cooperation to fit into the victim's underlying objectives and goals. Felson and colleagues (2002) note that victims are trying to "achieve something they value" (p.619). Second, the benefits of cooperation should outweigh the costs. Crime victims often denote immediate safety for themselves and others as the focus of a decision. Further, they indicate that the specifics of a victimization shape how the victim sees the benefits and risks of invoking law enforcement (Gottfredson \& Gottfredson, 1988). Specifically, offense seriousness, the victim-offender relationship, prior contact with the criminal justice system, and characteristics of the offense alter how an individual responds to victimization (Galvin \& Safer-Lichtenstein, 2018; Kaiser et al., 2017; O’Neal, 2017).

Most research to date has focused on the decision to report a crime to the police (Baumer \& Lauritsen, 2010; Galvin \& Safer-Lichtenstein, 2018; Rennison, 2007; Xie, 2014; Xie \& Lauritsen, 2012), however, there is emerging work on victim cooperation in police investigations and prosecutions - specifically as it relates to sexual assault and intimate partner violence 
(Kaiser et al., 2017; O’Neal, 2017). These studies suggest that victim and case characteristics have a large influence on the likelihood of cooperation. Kingsnorth and Macintosh (2004) found that attack severity, measured as the requirement of medical attention, increased the likelihood of cooperation. Alternatively, retaliation-based fears (a potential cost) were associated with lowered odds of cooperation. In a more recent study, Kaiser and colleagues (2017) indicate that substantial physical evidence, the existence of multiple victims, and the presence of witnesses were associated with higher odds of cooperation at the time of the investigation. Finally, using a sample of intimate partner sexual assault cases, O'Neal (2017) found that threats at the time of the incident reduced the likelihood of cooperation at the investigation stage. Overall, research suggests that the nature of the assault can influence the likelihood of cooperation; therefore, gun crime incidents may have unique costs. For this reason, we echo O'Neal (2017), who argues it is essential to develop crime-specific models and predictors of cooperation.

Community Perspectives

Although case characteristics play a large role in individual decisions, community characteristics can also shape the choice set and heuristics used when members make decisions (Gigerenzer \& Selten, 2001). Research suggests that residents of disadvantaged communities are less likely to activate the criminal justice system (Baumer, 2002; Clampet-Lundquist et al., 2015). Cultural explanations suggest that residents of minority and disadvantaged communities follow group norms in determining the appropriateness for reporting crimes. For instance, victims may feel that their allegiance to the community, which is threatened by incriminating persons from their own neighborhood, is more important than reporting a crime or assisting in its prosecution. Additionally, a substantial body of scholarship demonstrates that some communities are more likely to view the police and other agents of the criminal justice system as inadequate, 
unresponsive, and illegitimate to address their public safety needs (Kirk \& Matsuda, 2011; Kirk \& Papachristos, 2011; Sampson \& Bartusch, 1998). Such views may be conducive to the choice of vigilantism to deal with victimization over trusting the police to handle interpersonal conflict (Haas, de Keijser, \& Bruinsma, 2014).

Others argue that legal cynicism operates as a frame from which community residents shape the guidelines for cooperating with the police. Specifically, Clampet-Lundquist and colleagues (2015) contend that the stop-snitching movement is a protest against long-standing deceptive practices of law enforcement which have eroded trust in certain communities. Within this framework, variation in cooperation is hypothesized to arise from different levels of perceived legitimacy. Because legitimacy is generated from procedural justice components (procedural and distributive fairness, lawfulness, and effectiveness) (Tyler \& Fagan, 2008), it may be that there are important group differences in experiences with the justice system which affects legitimacy. Sampson and Bartusch (1998) find that residents of disadvantaged communities are less likely to trust the police and cooperate with investigations, despite high disapproval for criminal behaviors. Such community-level factors may be particularly salient for gun violence because it also concentrates in disadvantaged and segregated areas of cities (Braga, Papachristos, \& Hureau, 2010).

Overall, we propose that individual behaviors, like the decision to cooperate, arise from case-level factors but are conditioned by group norms and community cultures. Still, the research on victim cooperation is in its infancy. Minimally it lacks in both quantity of studies and breadth, particularly with respect to gun violence. The current research presents an examination of the predictors of cooperation in nonfatal gun assaults with attention to both individual and community-level predictors. 


\section{Methods and Data}

\section{The Current Study}

This study focuses on data from two Midwest cities, Indianapolis, Indiana and St. Louis, Missouri (see see see see Hipple, McGarrell, O’Brien, \& Huebner, 2017). Both cities currently, and historically, have higher rates of homicides and violent crime when compared to national rates. For the 2014 and 2015 study period, the Indianapolis homicide rate was 15.8 and 17.1 per 100,000 people whereas St. Louis had homicide rates of 49.9 and 59.2. The national homicide rate was 4.5 and 4.9 homicides per 100,000 people for 2014 and 2015 (Federal Bureau of Investigation, 2016). In addition, there is evidence that these communities have embedded gun cultures and deep entrenchment of poverty and segregation (Huebner, Martin, Moule, Pyrooz, \& Decker, 2016; McGarrell \& Chermak, 2004).

A multi-site analysis has several advantages. First, including two cities in the analysis strengthens external validity. Gun violence is a widespread and costly public health issue in the United States, yet, there is little comparative research of this type (Wintemute, 2015). In fact, most research on gun violence has focused on large communities that may not be representative of the gun crime nationally (Cohen \& Tita, 1999; Papachristos, 2009). Developing effective public approaches to gun crime, according to Hemenway and Miller (2013), starts with "good data systems that provide consistent and comparable detailed information across sites and over time” (p. 2034). This study is a first step in this effort; it is also timely. Indianapolis and St. Louis are among many Midwest cities that saw recent increases in homicides when much of the country was experiencing declines. A call has been made to study the intricacies of gun crime in cities with rising homicide rates (Rosenfeld, Gaston, Spivak, \& Irazola, 2017). 
Data

The focus of this research is on criminal nonfatal gun crime. For the purposes of this study, we define a criminal nonfatal shooting using two primary criteria. First, the incident had to meet the criteria of an aggravated assault according to both the Uniform Crime Reports (UCR) and the National Incident-Based Reporting System (NIBRS). The FBI defines an aggravated assault "as an unlawful attack by one person upon another for the purpose of inflicting severe or aggravated bodily injury" (Federal Bureau of Investigation, 2013a). Self-inflicted and accidental nonfatal shooting victims were excluded. Shootings ruled self-defense are not "unlawful" and were also omitted. Second, the incident must include physical injury (i.e., gunshot wound) directly from a firearm. A gunshot wound is defined as a penetrating injury caused by a projectile weapon with a powder discharge (i.e. an explosive) (Beaman, Annest, Mercy, Kresnow, \& Pollock, 2000). We used 18 U.S. Code $\S 921(a)(3)$ to guide our definition of a firearm because weapons that meet this definition are crime drivers and are most commonly subjected to regulation at the state level. Victims suffering from, for example, shrapnel wounds from broken glass or air gun injuries were excluded. ${ }^{i}$

Data for this study were collected from official police records and compiled into a single dataset. The total sample includes 1,091 nonfatal shooting victims, 688 from Indianapolis, Indiana and 403 from St. Louis, Missouri. Data from Indianapolis include all known nonfatal shootings that occurred in the city from January 1, 2014 to December 31, 2015. In St. Louis, a random sample of "aggravated assault with a gun" incidents were selected from the records management system during the same period. ${ }^{\text {ii }}$ Researchers only coded those cases that met the nonfatal shooting definition. ${ }^{\text {iii }}$ 
Both sites relied on official police data and case notes maintained by the respective police department. All cases were coded by hand and several steps were taken to assure the quality of the data. At the outset of the project, a data collection instrument was developed that included criterion for coding cases. In addition, a sample of data from each site was cross-coded to ensure inter-relater reliability. For the cooperation variable, because it was researcher interpreted and not an officer coded, at least two researchers coded this variable for each incident. Every code disagreement was noted and discussed and a final code was assigned after consensus was reached (Harry, Sturges, \& Klingner, 2005; Saldana, 2009). ${ }^{\text {iv }}$

\section{Dependent Variable}

The focus of the analysis is to understand how victim characteristics, circumstances of the crime incident, and the nature of the injury influence initial victim cooperation with the police. The dependent variable is a binary measure of victim cooperation $(1=$ victim cooperated with the police investigation of their case; $0=$ victim did not cooperate). Researchers coded a victim as uncooperative if he or she did not aid in the police investigation. Individuals were coded as uncooperative if they refused to talk to the police officer at the scene or hospital, did not respond to phone calls from the officer, or indicated no knowledge of the incident. If a victim was unable to talk to the police due to injury or cooperation could not be determined based on the data sources, researchers coded those cases as unknown and they were removed from the final analysis. Researchers erred on the side of the victim being cooperative; specifically, they assumed the victim was cooperative unless there were indications otherwise. ${ }^{\mathrm{v}}$

Descriptive statistics for the sample and by victim cooperation are presented in Table 1. Nearly $57 \%(n=596)$ of the nonfatal shooting victims are denoted as cooperative. At the 
bivariate level, we find that this group differs significantly from uncooperative victims on nearly every independent variable with the exception of wound location.

\section{[INSERT TABLE 1 ABOUT HERE]}

\section{Explanatory Variables}

Two dichotomous demographic measures are included: $\operatorname{sex}(1=$ male, $0=$ female $)$ and race $(1=$ nonwhite, 0 = white $) .{ }^{\text {vi }}$ Race is a central measure because research suggests that people of color are more likely to live in communities in which there is less trust of the police (Gau \& Brunson, 2010; Sampson \& Bartusch, 1998) and people of color are less likely to report crimes to the police (Avakame, Fyfe, \& McCoy, 1999; Xie, 2014; Xie \& Lauritsen, 2012). In contrast, there is evidence that women are more likely to cooperate with police (Kingsnorth \& Macintosh, 2004). In addition, a continuous measure of age was included and represents age of the victim at the time of the nonfatal shooting incident. In total, the sample was predominantly male (88\%) and nonwhite (88\%), and the average age of the victim was 28 years.

A measure of arrest record is also included $(1=$ victim had known arrest record; $0=$ victim had no known arrest record), and $68 \%$ of victims had a prior arrest record. ${ }^{\text {vii }}$ We include this measure to capture the victim-offender overlap present in many violent incidents (Jennings, Piquero, \& Reingle, 2012). Prior arrest also documents formal interactions with law enforcement, which could serve to influence perceptions of the police (Hurst, Frank, \& Lee Browning, 2000; Tyler \& Fagan, 2008). Individuals with prior criminal records are more likely to have subsequent contact with police (Erez, 1984). Prior work indicates that formal contacts are associated with negative perceptions of the police (Jesilow, Meyer, \& Namazzi, 1995; Maxson, Hennigan, \& Sloane, 2003; P. E. Smith \& Hawkins, 1973). 
Wound severity and motive are also central covariates. Earlier work suggests that victim participation in prosecution is less likely when physical attacks and injuries are more severe (Kingsnorth \& Macintosh, 2004). Gunshot wound severity was coded using the 1990 version of the Abbreviated Injury Severity Scale (AIS) (Baker \& O'Neill, 1976; Baker, O'Neill, Haddon Jr, \& Long, 1974). The AIS classifies an injury on an ordinal scale according to its severity based on body region. Data on wound location were collected in two phases. First, data on the location of each injury was denoted. In cases where the victim was shot multiple times, researchers coded all injuries and then selected the most serious wound location according to the 1990 AIS which is consistent with work of this type (Hipple \& Magee, 2017). Next, we collapsed wound location into a binary variable $(1=$ center mass including head, neck, chest or torso; $0=$ extremities including arms, legs, hands, or feet) under the assumption that center mass injuries represent the greater prospect of a life-threatening injury than an extremity injury. ${ }^{\text {vii }}$ The sample was evenly split between injuries that involved the center mass (49\%) and extremities.

Motive was captured at the nominal level using four categories including robbery, interpersonal dispute (e.g. domestic, argument, fight, or retaliation), drugs, and other/unknown motive. ${ }^{\text {ix }}$ Each incident was assigned one motive. Motive was recoded using three discrete dichotomous variables for each category. Robbery served as the reference category since research shows that individuals are most likely to cooperate in incidents that involve personal property (Block, 1974). In contrast, researchers have suggested that social distance is inversely related with cooperation and reporting; therefore, we would expect less cooperation in incidents involving interpersonal disputes (Black, 1983). In addition, we include a dichotomous measure of the incident location $(1=$ St. Louis; $0=$ Indianapolis $)$ to account for potential measurement differences between communities. 
Finally, two census-block group-level measures are included to capture community context. Prior work has identified disadvantage and racial composition as important structural antecedents that may shape community member's experiences with police and their ultimate likelihood to cooperate and report to law enforcement (Kirk \& Matsuda, 2011; Sampson, Raudenbush, \& Earls, 1997). Consistent with this work, we used principal components factor analyses to generate a measure of concentrated poverty. Original variables include the percentage of households living below the poverty line, the percentage of households utilizing food stamps, the percentage of female-headed households, and the percentage of adults unemployed, all taken from the U.S. Census American Community Survey (2013). ${ }^{\mathrm{x}}$ We also include a measure of the percentage nonwhite in the block group where the incident occurred. Analyses

We conduct a series of analyses with the goal of exploring predictors of victim cooperation in nonfatal shooting incidents. The first phase of the analysis, using logistic regression models (Long, 1997), considers the direct effect of victim demographics, incident characteristics, and neighborhood characteristics on the likelihood of victim cooperation in a nonfatal gun assault. The models assume all victims come to their decision to cooperate using similar information, but there is evidence to argue that race may condition responses to crime victimization (Rennison, 2007; Xie \& Lauritsen, 2012). As such, we introduce a series of interaction models. The models assess if racial effects may influence the effect of injury severity and motive on the decision to cooperate with the police. Doing so provides a nuanced understanding of if and how race affects the relationship between traditional rational choice variables and cooperation. 


\section{Findings}

Multivariate Analysis

Table 2 displays the results of the binary logistic regression. Male victims are approximately $50 \%$ less likely to cooperate with police. Additionally, older persons are more likely to cooperate. A one-year increase in age is associated with approximately a $1 \%$ increase in cooperation. Race and previous arrest record do not reach statistical significance. This finding is likely a product of robust standard errors.

\section{[INSERT TABLE 2 ABOUT HERE]}

Consistent with research of this type, a victim shot during an interpersonal dispute is less likely to cooperate with police compared to a victim of a robbery, and the effect is moderately large $(\mathrm{OR}=.50)$. Drug involved incidents are also less likely to include a cooperative victim and the effect is strong with an approximate $65 \%$ decline $(\mathrm{OR}=.35)$ in cooperation. Incidents which fall in the other/unknown motive category are the least likely to include a cooperative victim $(\mathrm{OR}=.19)$. This last finding should be interpreted with caution because uncooperative victims may be less likely to provide information on incident circumstances.

Community context also conditioned the likelihood of cooperation. Individuals living in impoverished communities are less likely to cooperate with the police; a one-unit increase in concentrated poverty is associated an $18 \%$ decline in cooperation. In contrast, the racial composition of a community is not significantly associated with cooperation. Cooperation is

nearly two times more likely in St. Louis compared to Indianapolis. ${ }^{\mathrm{xi}}$ We posit that these differences may be an artifact of differences in report timing and writing. Interaction Effects 
Model 2 and Model 3 test the moderating nature of race in determining likelihood of cooperation. In Model 2 (Table 3), we interact the injury and race measures. ${ }^{\text {xii }}$ Coefficients for the main effects in the interacted variables in Model 4 represent their conditional effects (for example, the center mass coefficient represents the log odds of a white person cooperating with a center mass wound, rather than an extremity wound when all other variables are held at their means). Thus, interpretation is best understood in terms of predicted probabilities.

\section{[INSERT TABLE 3 ABOUT HERE]}

Figure 1 compares the predicted probabilities of cooperation for whites and nonwhites depending on the severity of their injuries. We find that when injuries are limited to extremities, the predicted probability of cooperation among white and nonwhite victims is not significantly different ( $54 \%$ and $55 \%$ respectively). However, when victims sustain center mass wounds, injuries traditionally classified as more serious, white and nonwhite probabilities of cooperation diverge. Specifically, white victims have a $79 \%$ predicted probability of cooperation, yet nonwhites are at $57 \%$. This finding suggests that the willingness to cooperate among whites is contingent on the extent of the injury. In contrast, nonwhite victims do not become markedly more cooperative when confronted with potentially more serious center mass injuries.

\section{[INSERT FIGURE 1 ABOUT HERE]}

Model 3 further tests the moderating nature of race. In Model 1 (the main model, see Table 2), robbery serves as the referent category for incident motive. All other motives are associated with declines in the log odds of cooperation, presumably because it represents cases with more distant relationships between victim and offender. To examine how the relationship between robbery and cooperation may be contingent on race, we created a dummy variable for robbery and regressed cooperation on the full set of predictors as well as the moderator variable 
(robbery*nonwhite). Table 4 provides the log-odd coefficients for Model 3. Although this model utilizes a more simplistic measure of motive (and is somewhat less efficient than the noninteractive model), it is informative in that it allows us to see the conditional relationships between incident characteristics and victim cooperation. Again, we find that race moderates the relationship between circumstance and cooperation.

\section{[INSERT TABLE 4 ABOUT HERE]}

Under these model specifications, we find that, for whites, the predicted probability of cooperating increases slightly—but not significantly—when robbery is the motive ( $73 \%$ t versus $69 \%)$. For nonwhites, these differences are more dramatic. The predicted probability of cooperation among nonwhites when robbery is the motive is $83 \%$, however, when any other motive is identified, the predicted probability of victim cooperation among nonwhites is $51 \%$ (see Figure 2).

\section{[INSERT FIGURE 2 ABOUT HERE]}

The stark contrast in cooperation within nonwhites based on the alleged motivation of the gun violence incident indicates that nonwhite victims may consider their relational distance to a suspect in their decision to cooperate. Whereas white victims are similarly likely to cooperate with police — whether the incident resulted from interpersonal disputes or an arguably less socially intimate scenario such as a robbery — the evidence suggests that nonwhite victims do not invoke the police to intercede in cases of domestic violence, arguments among acquaintances, and drug dealing. ${ }^{\text {xii }}$

In addition to the significant interactions in Model 2 and Model 3, it should also be noted that modelling the interactions is of consequence to criminal arrest record as it reaches significance in the fully specified models (Models 2 and 3). Arrest records are associated with 
just over a 25\% decline in the odds of cooperation in Model 2 (Table 3) and Model 3 (Table 4). This slight suppression of the arrest record in Model 1 is due in part to the conservative, clustered standard errors. In Models 2 and 3, where interaction terms clear up some of the prediction error in the model, the obscured relationship between prior arrest and cooperation is brought more clearly into focus.

\section{Discussion and Conclusion}

Victim behavior can play a central role in the criminal justice system, yet, most research implies that victims do not report crime to the police and are often reluctant to cooperate in investigations of personal crimes (Erez \& Tontodonato, 1990; Goodman et al., 1999; Kaiser et al., 2017; O’Neal, 2017). Little research has documented the factors that best determine victim involvement in criminal investigations. This work is a first step in exploring the factors that influence victim cooperation in nonfatal gun assault incidents. Studying cooperation in gun crime incidents is particularly timely and important for policy given that recent reports have highlighted health and social costs of gun violence for citizens and communities (Howell \& Abraham, 2013; Irvin-Erickson, Bai, Gurvis, \& Mohr, 2016).

In total, $43 \%$ of victims did not cooperate with the police investigation of their case. The cooperation rate is low but conforms with crime reporting rates that hover around $50 \%$ (Truman \& Morgan, 2016). The research findings suggest that individual and community level factors can play a role in understanding victim behavior. There is also initial support for the rational choice perspective (Gottfredson \& Gottfredson, 1988). Shooting motive was a central indicator in the initial multivariate models. Victims involved in interpersonal disputes or drug-related incidents are less likely to cooperate with the police when compared with robbery-motivated gun crimes. Individuals involved in interpersonal disputes have less social distance from the offender 
potentially making cooperation more costly. Similarly, cooperation in a drug motivated criminal investigation could raise the potential for retaliation and increase the risk of subsequent investigation by law enforcement (Jacobs \& Wright, 2006). Individuals living in more impoverished communities also have lower likelihoods of cooperation. This finding conforms with cultural perspectives of crime, which proposes that residents of these communities may have less investment and trust in formal institutions like the police (Anderson, 1999).

We also estimate a series of interactions to consider how and if race influences cooperation. Although race did not have a direct effect on cooperation in the initial multivariate models, it does have a moderating effect. Specifically, we find that white victims with injuries to the center mass area were more likely to cooperate, but the same relationship was not observed for nonwhite victims. Given that minority communities have had a historically tenuous relationship with law enforcement (Gau \& Brunson, 2010), these results may indicate that perceived police illegitimacy may lessen the victim's likelihood of cooperating even in situations where the benefits of cooperating appear to outweigh the costs (White, Mulvey, \& Dario, 2016). Similarly, white victims were more likely to cooperate with police, net of motive, which may indicate a robust trust of law enforcement to intercede on their behalf. In contrast, nonwhite victims have lower predicted probabilities of cooperation when they have less social distance between themselves and the offender, as is the case with robbery incidents.

This research is noteworthy for policy and highlights the centrality of victims in gun crime incidents. There is a need for more research and informed policy on the extent and manner to which the criminal justice system can facilitate victim participation in nonfatal shooting investigations. Increasing victim participation can have two potentially positive outcomes. First increasing trust in the police and victim participation in investigations has the potential to reduce 
violent retaliation. Research shows that gun crimes, and the highly interpersonal interactions that precede gun assaults, can engender a high risk for retaliatory violence (Cohen \& Tita, 1999; Decker, 1996; Messner et al., 1999; Morenoff, Sampson, \& Raudenbush, 2001; Rosenfeld, Bray, \& Egley, 1999; W. R. Smith, Frazee, \& Davison, 2000). In communities where victims are reluctant to trust the police, they are more likely to take rivalries and order maintenance into their own hands, using self-help strategies (Jacobs \& Wright, 2006). Retaliatory violence can spill into surrounding neighborhoods (Decker, 1996; Papachristos, 2009; Tita \& Griffiths, 2005) continuing the cycle of gun violence and the prevalence of gun assaults. Understanding the factors that facilitate and detract from victim participation may help police and other agencies develop programming and policies that could potentially build trust and encourage victim reporting with the long-term goal of reducing violent retaliation.

Second, victim involvement can help facilitate the arrest, prosecution, and potential incarceration of active gun offenders. Research suggests that victim participation is one of the most salient predictors of case processing. For example, using a sample of non-stranger sexual assault cases, Spohn and Tellis (2014) found that victim cooperation during a law enforcement investigation was the most important predictor of suspect arrest. Similarly, Dawson and Dinovitzer (2001) found that prosecution of the perpetrator in a specialized court was seven times more likely in cases where the prosecutor viewed the victim as cooperative. Improved case processing also has the potential to reduce crime if high rate offenders are detained. There is evidence that a small proportion of offenders are responsible for a disproportionate amount of crime and that there are tight networks of gun-involved offenders (Cook \& Laub, 2002; Dobrin, 2001; Engel, Tillyer, \& Corsaro, 2013; Papachristos, Wildeman, \& Roberto, 2015). As demonstrated in sexual assault cases (O'Neal et al., 2015), improved victim cooperation could 
result in better cases where shooters are prosecuted, convicted, and incarcerated - resulting in potential declines in gun crime overall. In short, improving case processing of gun crimes is particularly important as law enforcement agencies across the country struggle with declining clearance rates and negative police-community relations (Rosenfeld et al., 2017).

Although our study contributes to the literature in important ways, we temper our findings in consideration of the study's limitations. First, researchers coded data from official police files that are limited in scope and are based on the officer's perception and characterization of the event. The cooperation measure does not capture how the nature of the police-community member interaction or the officer's perception of the individual or incident might have influenced the characterization of the event. Researchers have documented that cynicism and distrust in the public can influence an officer's worldview (Skolnick, 1994; Van Maanen, 1978). Limitations also exist in the measurement of motive. Criminal motive was not always evident to the investigator at the time he or she created the source document. In addition, victims may obscure the true motive, leaving researchers to rely on investigator notes alone. Likewise, there is evidence that peer relationships, particularly gang membership, can influence gun crime and police-community interactions (Decker \& Van Winkle, 1996; Huebner et al., 2016). Gang information was not denoted consistently in casefiles for the study sites. Given the centrality of this measure for the study of violent crime, future research should capture how gang membership influences victim decision-making.

Similarly, the nature of these data allowed us to consider why victims were not cooperative, but researchers should also document the reasons victims chose to cooperate with the police. Using qualitative interviews with victims, particularly if they could be repeated over the life course of the case process, would yield important insight. Prior experience with the 
police of any kind, particularly as a victim, could influence victim cooperation (White et al., 2016). Victim cooperation may also change over time (Dawson \& Dinovitzer, 2001; Ford, 1991). Victim informed data would allow researchers to better characterize the nature of the victimoffender relationship and to consider how cooperation may change during case processing. In conclusion, this study explores the individual and community factors that influence a victim's decision to cooperate in the police investigation of their case. This work highlights the myriad factors that influence cooperation; particularly the complex ways that race may influence victim cooperation. The results suggest that we cannot ignore victim cooperation when looking for ways to respond to and prevent gun violence. Indeed, the victim may be the 'break' needed by law enforcement to arrest a violent offender thus preventing future violence. As noted by Birdsall, Kirby, and McManus (2017), increasing our understanding of police-victim interactions will only serve to improve victim cooperation at all criminal justice system decision points. 
Table 1. Descriptive statistics for full sample and by dependent variable outcome

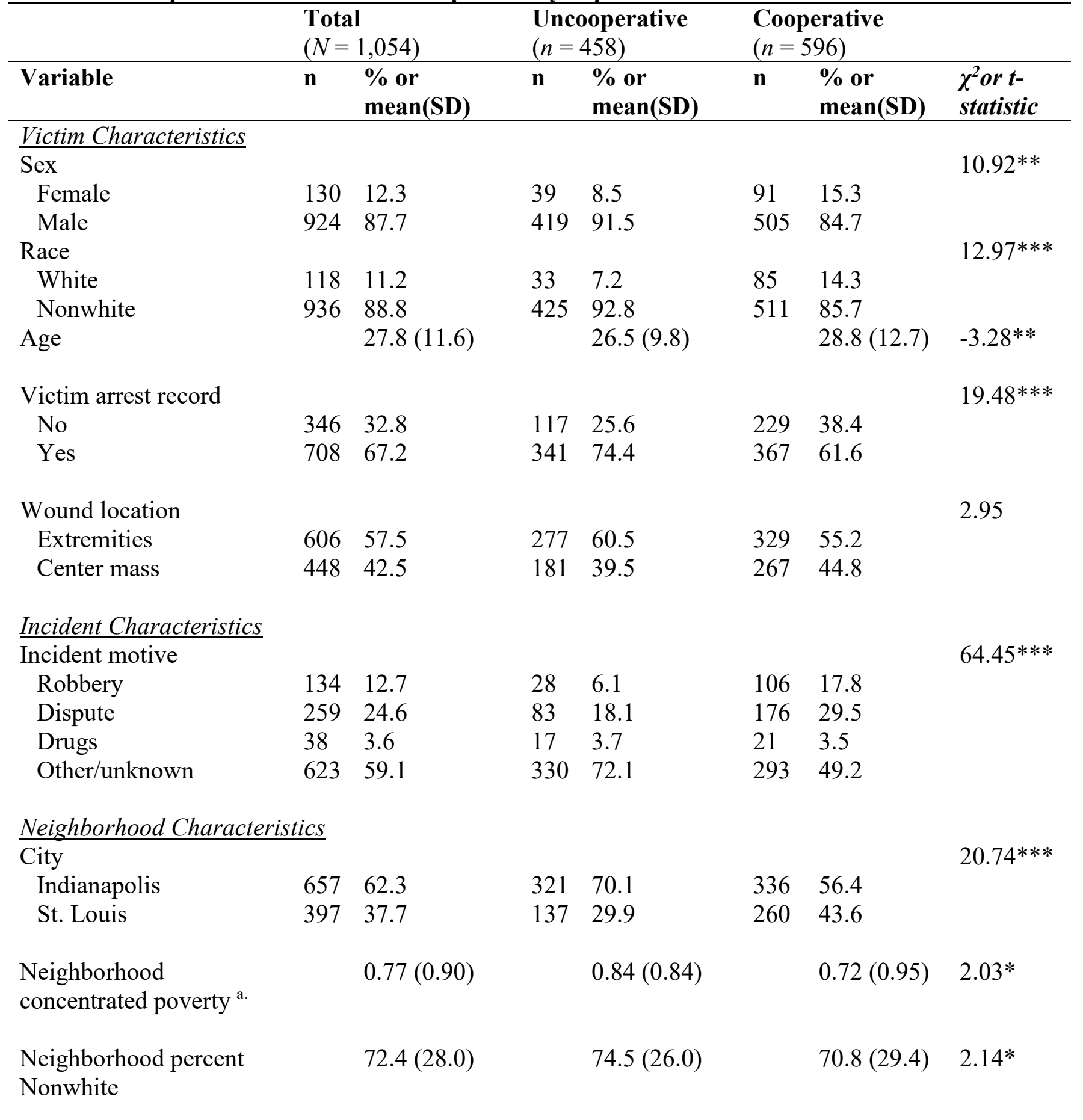

a. Principal components factor variable estimated in STATA using \% below poverty, \% female-headed household, $\%$ receiving food stamps, and $\%$ unemployed.

${ }^{*} p<.05,{ }^{* *} p<.01,{ }^{* * *} p<.001$ 
Table 2. Binary logistic regression for motive, gunshot wound location, demographics and cooperation $($ Model 1) $($ Cooperative $=1)$

\begin{tabular}{|c|c|c|c|c|c|c|}
\hline \multirow{3}{*}{$\begin{array}{l}(n=1,054) \\
\text { Predictor }\end{array}$} & \multirow[b]{3}{*}{$\beta$} & \multirow[b]{3}{*}{$\mathrm{SE}$} & \multirow[b]{3}{*}{ Sig. } & \multirow{3}{*}{$\begin{array}{c}{[\operatorname{Exp}(\mathrm{b})]} \\
\text { Odds Ratio }\end{array}$} & \multicolumn{2}{|c|}{ 95\% Confidence } \\
\hline & & & & & \multicolumn{2}{|c|}{$\underline{\text { Interval }}$} \\
\hline & & & & & Lower & Upper \\
\hline \multicolumn{7}{|l|}{ Victim Characteristics } \\
\hline Male & -0.699 & 0.232 & $.003 * *$ & 0.497 & 0.315 & 0.784 \\
\hline Nonwhite & -0.468 & 0.239 & .050 & 0.626 & 0.392 & 1.000 \\
\hline Age & 0.013 & 0.006 & $.040 *$ & 1.013 & 1.001 & 1.025 \\
\hline $\begin{array}{l}\text { Arrest Record } \\
\text { Incident Characteristics }\end{array}$ & -0.294 & 0.155 & .057 & 0.745 & 0.550 & 1.009 \\
\hline $\begin{array}{l}\text { Center Mass Wound } \\
\text { Motive }\end{array}$ & 0.203 & 0.148 & .172 & 1.225 & 0.915 & 1.638 \\
\hline Interpersonal Dispute & -0.713 & 0.266 & $.007 * *$ & 0.490 & 0.291 & 0.825 \\
\hline Drugs & -1.050 & 0.437 & $.016^{*}$ & 0.350 & 0.149 & 0.824 \\
\hline Other/Unknown & -1.681 & 0.252 & $.000 * * *$ & 0.186 & 0.114 & 0.305 \\
\hline St. Louis & 1.134 & 0.177 & $.000 * * *$ & 3.109 & 0.787 & 1.481 \\
\hline \multicolumn{7}{|c|}{ Neighborhood Characteristics } \\
\hline Concentrated Poverty & -0.195 & 0.095 & $.041 *$ & 0.823 & 0.683 & 0.992 \\
\hline Percent Nonwhite & -0.003 & 0.003 & .367 & 0.997 & 0.991 & 1.004 \\
\hline Constant & 2.258 & 0.454 & $.000 * * *$ & 9.563 & & \\
\hline
\end{tabular}

Overall model evaluation

Chi square $\quad 113.94$

-2 log likelihood $\quad 1286.406$

Nagelkerke R Square .185

${ }^{*} p<.05, * * p<.01, * * * p<.001$

Models estimated with cluster robust standard errors accounting for correlation at the block-group level. 
Table 3. Binary logistic regression predicting cooperation with wound severity and race interacted (Model 2) $($ Cooperative $=1)$

\begin{tabular}{|c|c|c|c|c|c|c|}
\hline \multicolumn{4}{|l|}{$(n=1,054)$} & \multirow{2}{*}{$\begin{array}{c}{[\operatorname{Exp}(\mathrm{b})]} \\
\text { Odds Ratio }\end{array}$} & \multicolumn{2}{|c|}{$\frac{95 \% \text { Confidence }}{\text { Interval }}$} \\
\hline Predictor & $\beta$ & SE & Sig. & & Lower & Upper \\
\hline \multicolumn{7}{|l|}{ Victim Characteristics } \\
\hline Male & -0.709 & 0.234 & $.002 * *$ & 0.492 & 0.311 & 0.778 \\
\hline Nonwhite & 0.032 & 0.320 & .920 & 1.033 & 0.551 & 1.935 \\
\hline Age & 0.013 & 0.006 & $.038^{*}$ & 1.013 & 1.001 & 1.025 \\
\hline \multicolumn{7}{|c|}{ Incident Characteristics } \\
\hline Center Mass Wound & 1.350 & 0.523 & $.010^{*}$ & 3.858 & 1.385 & 10.744 \\
\hline Interpersonal Dispute & -0.750 & 0.266 & $.005 * *$ & 0.473 & 0.280 & 0.797 \\
\hline Drugs & -1.069 & 0.459 & $.020 *$ & 0.343 & 0.140 & 0.843 \\
\hline Other/Unknown & -1.722 & 0.254 & $.000^{* * *}$ & 0.179 & 0.109 & 0.294 \\
\hline St. Louis & 1.141 & 0.176 & $.000^{* * *}$ & 3.130 & 2.217 & 4.420 \\
\hline \multicolumn{7}{|c|}{ Neighborhood Characteristics } \\
\hline Concentrated Poverty & -0.205 & 0.096 & $.033^{*}$ & 0.815 & 0.675 & 0.984 \\
\hline Percent Nonwhite & -0.002 & 0.003 & .459 & 0.998 & 0.991 & 1.004 \\
\hline \multicolumn{7}{|l|}{ Center Mass X } \\
\hline Nonwhite & -1.261 & 0.543 & $.020^{*}$ & 0.283 & 0.098 & 0.822 \\
\hline Constant & 1.820 & 0.481 & $.000^{* * *}$ & 6.170 & 2.402 & 15.853 \\
\hline \multicolumn{7}{|c|}{ Overall model evaluation } \\
\hline Chi square & 118.40 & $.000 * * *$ & & & & \\
\hline$-2 \log$ likelihood & 1279.518 & & & & & \\
\hline Nagelkerke R Square & .193 & & & & & \\
\hline
\end{tabular}


Table 4. Binary logistic regression predicting cooperation with robbery motive and race interacted (Model 3) $($ Cooperative $=1)$

\begin{tabular}{|c|c|c|c|c|c|c|}
\hline \multicolumn{4}{|l|}{$(n=1,054)$} & \multirow{2}{*}{$\begin{array}{c}{[\operatorname{Exp}(b)]} \\
\text { Odds Ratio }\end{array}$} & \multicolumn{2}{|c|}{$\begin{array}{l}\text { 95\% Confidence } \\
\text { Interval }\end{array}$} \\
\hline Predictor & $\beta$ & SE & Sig. & & Lower & Upper \\
\hline \multicolumn{7}{|l|}{ Victim Characteristics } \\
\hline Male & -0.622 & 0.217 & $.004 * *$ & 0.537 & 0.351 & 0.822 \\
\hline Nonwhite & -0.829 & 0.264 & $.002 * *$ & 0.437 & 0.260 & 0.732 \\
\hline Age & 0.015 & 0.006 & $.016^{*}$ & 1.015 & 1.003 & 1.028 \\
\hline Arrest Record & -0.310 & 0.151 & $.039^{*}$ & 0.733 & 0.546 & 0.985 \\
\hline \multicolumn{7}{|l|}{ Incident Characteristics } \\
\hline Center Mass Wound & 0.208 & 0.144 & 149 & 1.232 & 0.928 & 1.634 \\
\hline St. Louis & 1.053 & 0.170 & $.000^{* * *}$ & 2.867 & 2.055 & 3.999 \\
\hline \multicolumn{7}{|c|}{ Neighborhood Characteristics } \\
\hline Concentrated Poverty & -0.231 & 0.095 & $.015^{*}$ & 0.794 & 0.659 & 0.956 \\
\hline Percent Nonwhite & -0.004 & 0.003 & .200 & 0.996 & 0.989 & 1.002 \\
\hline Robbery X Nonwhite & 1.381 & 0.570 & $.015^{*}$ & 3.981 & 1.303 & 12.161 \\
\hline Constant & 1.240 & .389 & $.001 * *$ & 3.455 & 1.612 & 7.408 \\
\hline \multicolumn{7}{|l|}{ Overall model evaluation } \\
\hline Chi square & 115.47 & $.000 * * *$ & & & & \\
\hline$-2 \log$ likelihood & 1315.498 & & & & & \\
\hline Nagelkerke R Square & .153 & & & & & \\
\hline
\end{tabular}

${ }^{*} \mathrm{p}<.05,{ }^{* *} \mathrm{p}<.01,{ }^{* * *} \mathrm{p}<.001$

Models estimated with cluster robust standard errors accounting for correlation at the block-group level. 


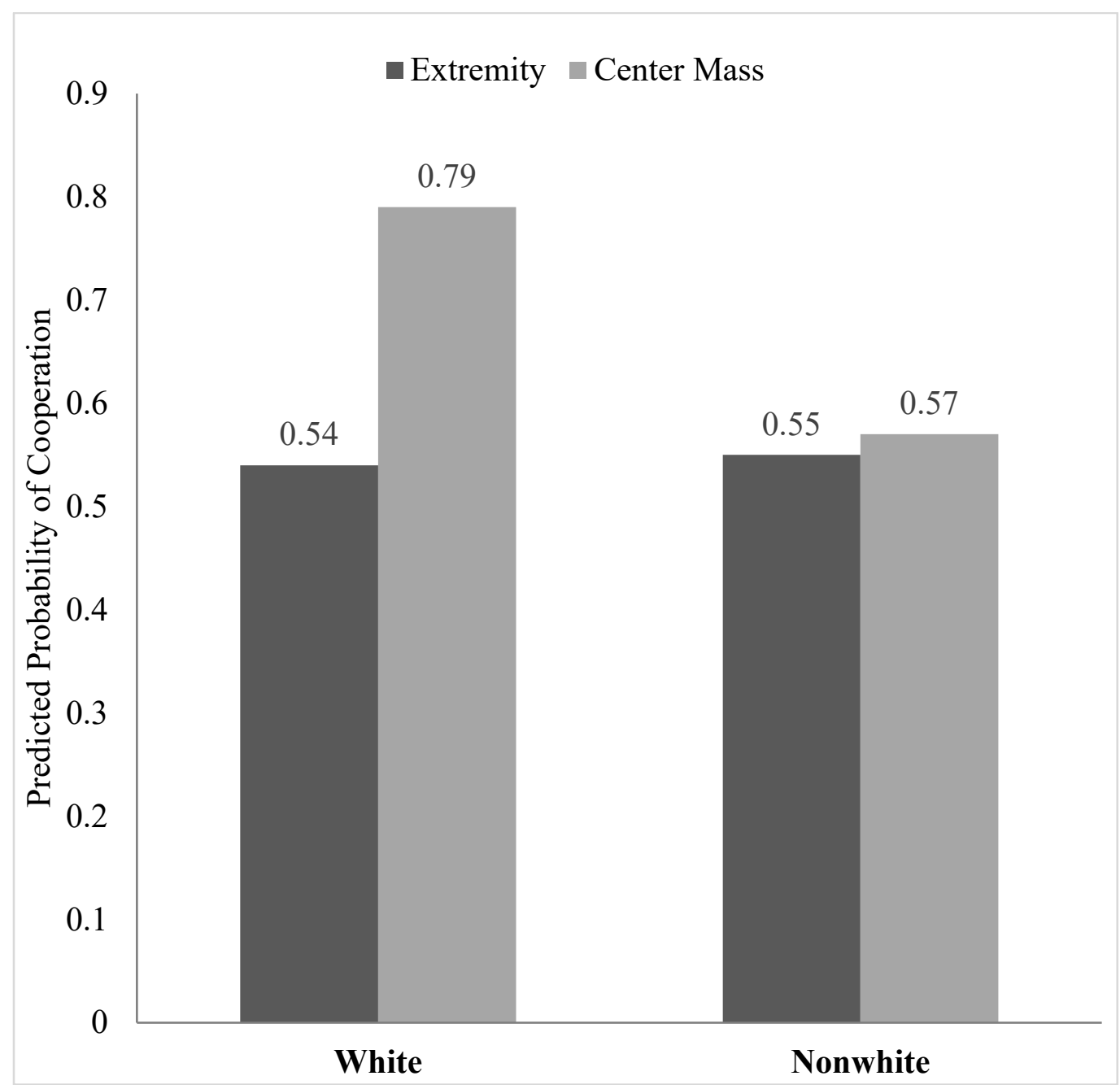

Figure 1. Predicted Probabilities of Cooperation: Race and Wound Severity 


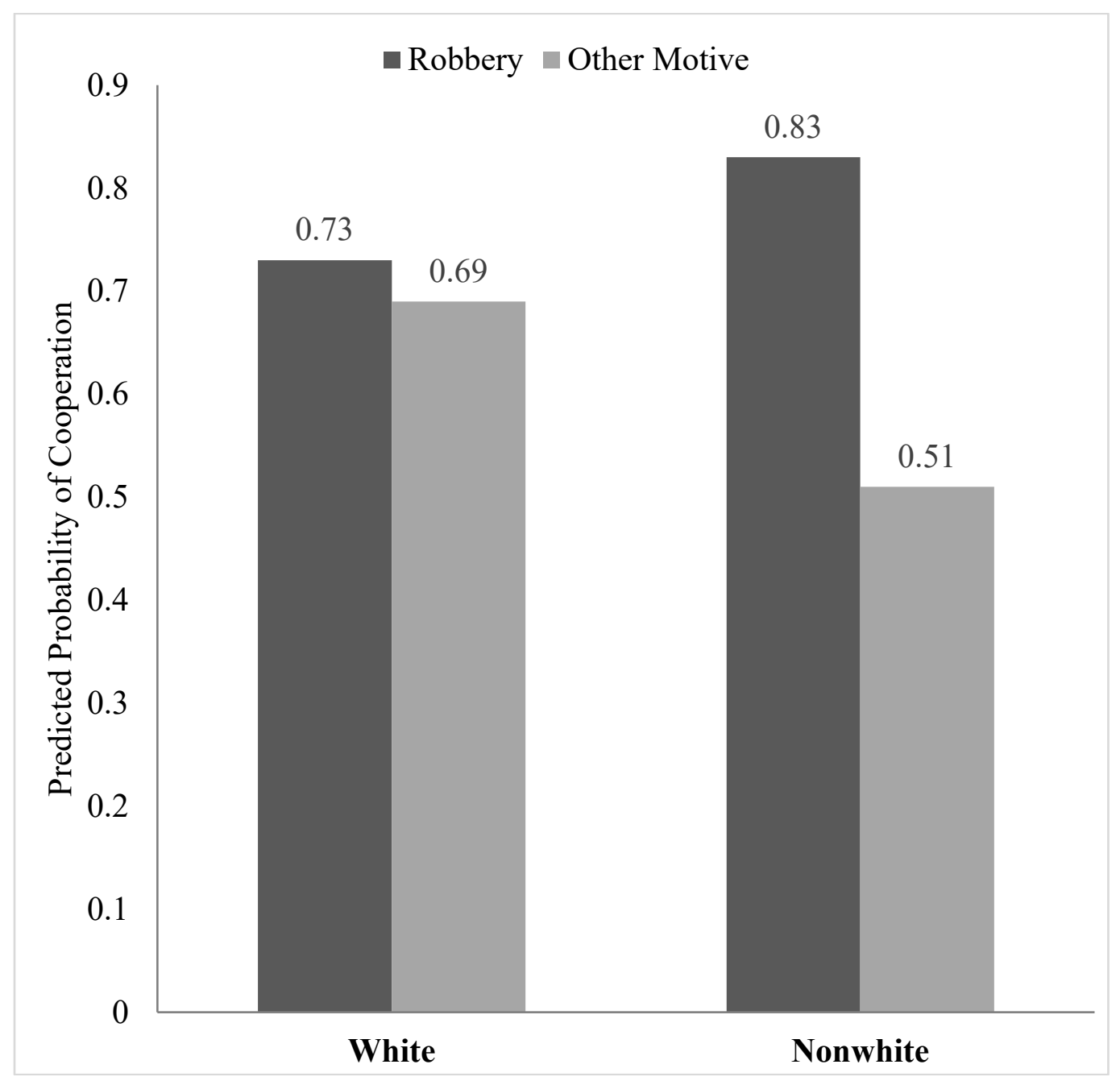

Figure 2. Predicted Probabilities of Cooperation: Race and Shooting Motive 


\section{References}

Anderson, E. (1999). Code of the street: Decency, violence, and the moral life of the inner city. New York, NY: Norton.

Avakame, E. F., Fyfe, J. J., \& McCoy, C. (1999). "Did you call the police? What did they do?" An empirical assessment of Black's theory of mobilization of law. Justice Quarterly, 16(4), 765-792. doi:10.1080/07418829900094361

Baker, S. P., \& O'Neill, B. (1976). The injury severity score: An update. The Journal of Trauma and Acute Care Surgery, 16(11), 882-885.

Baker, S. P., O'Neill, B., Haddon Jr, W., \& Long, W. B. (1974). The injury severity score: A method for describing patients with multiple injuries and evaluating emergency care. The Journal of Trauma and Acute Care Surgery, 14(3), 187-196.

Baumer, E. P. (2002). Neighborhood disadvantage and police notification by victims of violence. Criminology, 40(3), 579-616. doi:10.1111/j.1745-9125.2002.tb00967.x

Baumer, E. P., \& Lauritsen, J. L. (2010). Reporting crime to the police, 1973-2005: A multivariate analysis of long-term trends in the National Crime Survey (NCS) and National Crime Victimization Survey (NCVS). Criminology, 48(1), 131-185. doi:10.1111/j.1745-9125.2010.00182.x

Beaman, V., Annest, J. L., Mercy, J. A., Kresnow, M.-J., \& Pollock, D. A. (2000). Lethality of firearm-related injuries in the United States population. Annals of emergency medicine, 35(3), 258-266. doi:10.1016/S0196-0644(00)70077-1

Birdsall, N., Kirby, S., \& McManus, M. (2017). Police-victim engagement in building a victim empowerment approach to intimate partner violence cases. Police Practice and Research, 18(1), 75-86. doi:10.1080/15614263.2016.1230061 
Black, D. (1983). Crime as social control. American Sociological Review, 48(1), 34-45. doi:10.2307/2095143

Block, R. (1974). Why notify the police: The victim's decision to notify the police of an assault. Criminology, 11(4), 555-569. doi:10.1111/j.1745-9125.1974.tb00614.x

Braga, A. A., Papachristos, A. V., \& Hureau, D. M. (2010). The concentration and stability of gun violence at micro places in Boston, 1980-2008. Journal of Quantitative Criminology, 26(1), 33-53. doi:10.2307/23367576

Clampet-Lundquist, S., Carr, P. J., \& Kefalas, M. J. (2015). The sliding scale of snitching: A qualitative examination of snitching in three Philadelphia communities. Sociological Forum, 30(2), 265-285. doi:10.1111/socf.12162

Cohen, J., \& Tita, G. (1999). Diffusion in homicide: Exploring a general method for detecting spatial diffusion processes. Journal of Quantitative Criminology, 15(4), 451-493. doi:10.1023/a:1007596225550

Cook, P. J., \& Laub, J. H. (2002). After the epidemic: Recent trends in youth violence in the United States. Crime and Justice, 29, 1-37. doi:10.1086/652218

Dawson, M., \& Dinovitzer, R. (2001). Victim cooperation and the prosecution of domestic violence in a specialized court. Justice Quarterly, 18(3), 593-622. doi:10.1080/07418820100095031

Decker, S. H. (1996). Collective and normative features of gang violence. Justice Quarterly, 13(2), 243-264.

Decker, S. H., \& Van Winkle, B. (1996). Life in the gang: family, friends, and violence. Cambridge: Cambridge University Press. 
Dobrin, A. (2001). The risk of offending on homicide victimization: A case control study. Journal of Research in Crime and Delinquency, 38(2), 154-173. doi:10.1177/0022427801038002003

Engel, R. S., Tillyer, M. S., \& Corsaro, N. (2013). Reducing gang violence using focused deterrence: Evaluating the Cincinnati Initiative to Reduce Violence (CIRV). Justice Quarterly, 30(3), 403-439. doi:10.1080/07418825.2011.619559

Erez, E. (1984). Self-defined 'desert' and citizens' assessment of the police. Journal of Criminal Law and Criminology, 75, 1276-1299.

Erez, E., \& Tontodonato, P. (1990). The effect of victim participation in sentencing on sentence outcome. Criminology, 28(3), 451-474. doi:10.1111/j.1745-9125.1990.tb01334.x

Federal Bureau of Investigation. (2013a). Crime in the United States, 2012: Aggravated assault. Retrieved from https://www.fbi.gov/about-us/cjis/ucr/crime-in-the-u.s/2012/crime-in-theu.s.-2012/violent-crime/aggravated-assault

Federal Bureau of Investigation. (2013b). Criminal Justice Information Services (CJIS) Division Uniform Crime Reporting Program (UCR). Retrieved from https://www.fbi.gov/aboutus/cjis/ucr/nibrs/summary-reporting-system-srs-user-manual

Federal Bureau of Investigation. (2016). Crime in the United States, 2015. Retrieved from https:/ucr.fbi.gov/crime-in-the-u.s/2015/crime-in-the-u.s.-2015

Felson, R. B., Messner, S. F., Hoskin, A. W., \& Deane, G. (2002). Reasons for reporting and not reporting domestic violence to the police. Criminology, 40(3), 617-648. doi:10.1111/j.1745-9125.2002.tb00968.x 
Fisher, B. S., Daigle, L. E., Cullen, F. T., \& Turner, M. G. (2003). Reporting sexual victimization to the police and others: Results from a national-level study of college women. Criminal Justice and Behavior, 30(1), 6-38. doi:10.1177/0093854802239161

Ford, D. A. (1991). Prosecution as a victim power resource: A note on empowering women in violent conjugal relationships. Law \& Society Review, 25(2), 313-334. doi:10.2307/3053801

Galvin, M. A., \& Safer-Lichtenstein, A. (2018). Same question, different answers: Theorizing victim and third party decisions to report crime to the police. Justice Quarterly, 35(6). doi:10.1080/07418825.2017.1353123

Gau, J. M., \& Brunson, R. K. (2010). Procedural justice and order maintenance policing: A study of inner-city young men's perceptions of police legitimacy. Justice Quarterly, 27(2), 255279. doi:10.1080/07418820902763889

Gigerenzer, G., \& Selten, R. (2001). Rethinking rationality. In G. Gigerenzer \& R. Selten (Eds.), Bounded rationality: The adaptive toolbox (pp. 1-12). Cambridge, MA: The MIT Press.

Goodman, L., Bennett, L., \& Dutton, M. A. (1999). Obstacles to victims' cooperation with the criminal prosecution of their abusers: The role of social support. Violence and Victims, 14(4), 427-444. Retrieved from http://www.ingentaconnect.com/content/springer/vav/1999/00000014/00000004/art00007 .doi:10.1891/0886-6708.14.4.427

Gottfredson, M. R., \& Gottfredson, D. M. (1988). Decision making in criminal justice: Toward the rational exercise of discretion (2nd ed.). New York: Plenum Press.

Gupta, M. (2007). Mandatory reporting laws and the emergency physician. Annals of emergency medicine, 49(3), 369-376. doi:10.1016/j.annemergmed.2006.05.017 
Haas, N. E., de Keijser, J. W., \& Bruinsma, G. J. N. (2014). Public support for vigilantism, confidence in police and police responsiveness. Policing and Society, 24(2), 224-241. doi:10.1080/10439463.2013.784298

Harry, B., Sturges, K. M., \& Klingner, J. K. (2005). Mapping the process: An exemplar of process and challenge in Grounded Theory analysis. Educational Researcher, 34(2), 313. doi: $10.3102 / 0013189 \times 034002003$

Hemenway, D., \& Miller, M. (2013). Public health approach to the prevention of gun violence. The New England journal of medicine, 368(21), 2033-2035. doi:10.1056/NEJMsb1302631

Hipple, N. K., \& Magee, L. A. (2017). The difference between living and dying: Victim characteristics and motive among nonfatal shooting and gun homicides. Violence and Victims, 32(6), 977-977. doi:10.1891/0886-6708

Hipple, N. K., McGarrell, E. F., O’Brien, M., \& Huebner, B. M. (2017). Gun crime incident reviews as a strategy for enhancing problem solving and information sharing. Journal of Crime and Justice, 40(1), 50-67. doi:10.1080/0735648X.2016.1155303

Howell, E. M., \& Abraham, P. (2013). The hospital costs of firearm assaults. Washington, DC: Urban Institute.

Huebner, B. M., Martin, K., Moule, R. K., Pyrooz, D., \& Decker, S. H. (2016). Dangerous places: Gang members and neighborhood levels of gun assault. Justice Quarterly, 33(5), 836-862. doi:10.1080/07418825.2014.984751

Hurst, Y. G., Frank, J., \& Lee Browning, S. (2000). The attitudes of juveniles toward the police: A comparison of black and white youth. Policing: An International Journal of Police Strategies and Management, 23(1), 37-53. doi:10.1108/13639510010314607 
Irvin-Erickson, Y., Bai, B., Gurvis, A., \& Mohr, E. (2016). The effect of gun violence on local economies. Washington, DC: Urban Institute.

Jacobs, B. A., \& Wright, R. (2006). Street justice: Retaliation in the criminal underworld. New York, NY: Cambridge University Press.

Jennings, W. G., Piquero, A. R., \& Reingle, J. M. (2012). On the overlap between victimization and offending: A review of the literature. Aggression and Violent Behavior, 17(1), 16-26. doi:10.1016/j.avb.2011.09.003

Jesilow, P., Meyer, J. o., \& Namazzi, N. (1995). Public attitudes toward the police. American Journal of Police, 14(2), 67-88. doi:10.1108/07358549510102767

Kaiser, K. A., O’Neal, E. N., \& Spohn, C. (2017). “Victim refuses to cooperate”: A focal concerns analysis of victim cooperation in sexual assault cases. Victims \& Offenders, 2, 297-322. doi:10.1080/15564886.2015.1078864

Kalesan, B., Adhikarla, C., Pressley, J. C., Fagan, J. A., Xuan, Z., Siegel, M. B., \& Galea, S. (2017). The hidden epidemic of firearm injury: Increasing firearm injury rates during 2001-2013. American Journal of Epidemiology, 185(7), 546-553.

doi:10.1093/aje/kww147

Kingsnorth, R. F., \& Macintosh, R. C. (2004). Domestic violence: Predictors of victim support for official action. Justice Quarterly, 21(2), 301-328. doi:10.1080/07418820400095821

Kirk, D. S., \& Matsuda, M. (2011). Legal cynicism, collective efficacy, and the ecology of arrest. Criminology, 49(2), 443-472. doi:10.1111/j.1745-9125.2011.00226.x

Kirk, D. S., \& Papachristos, A. V. (2011). Cultural mechanisms and the persistence of neighborhood violence. American Journal Of Sociology, 116(4), 1190-1233. doi: $10.1086 / 655754$ 
Long, J. S. (1997). Regression models for categorical and limited dependent variables (Vol. 7). Thousand Oaks, CA: Sage Publications, Inc.

Maxson, C. L., Hennigan, K., \& Sloane, D. C. (2003). Factors that influence public opinion of the police. Washington, DC: US Department of Justice, Office of Justice Programs, National Institute of Justice.

McGarrell, E. F., \& Chermak, S. (2004). Strategic approaches to reducing firearms violence: Final report on the Indianapolis Violence Reduction Partnership. Washington, DC: National Institute of Justice, Office of Justice Programs, U.S. Department of Justice.

Messner, S. F., Anselin, L., Baller, R. D., Hawkins, D. F., Deane, G., \& Tolnay, S. E. (1999). The spatial patterning of county homicide rates: An application of exploratory spatial data analysis. Journal of Quantitative Criminology, 15(4), 423-450. doi:10.1023/a:1007544208712

Morenoff, J. D., Sampson, R. J., \& Raudenbush, S. W. (2001). Neighborhood inequality, collective efficacy, and the spatial dynamics of urban violence. 39(3), 517-558. doi:10.1111/j.1745-9125.2001.tb00932.x

O’Neal, E. N. (2017). Victim cooperation in intimate partner sexual assault cases: A mixed methods examination. Justice Quarterly, 34(6), 1014-1043. doi: $10.1080 / 07418825.2016 .1244285$

O’Neal, E. N., \& Spohn, C. (2017). When the perpetrator is a partner. Violence Against Women, 23(6), 707-729. doi:10.1177/1077801216650289

O’Neal, E. N., Tellis, K., \& Spohn, C. (2015). Prosecuting intimate partner sexual assault: Legal and extra-legal factors that influence charging decisions. Violence Against Women, 21(10), 1237-1258. doi:10.1177/1077801215591630 
Papachristos, A. V. (2009). Murder by structure: Dominance relations and the social structure of gang homicide. American Journal Of Sociology, 115(1), 74-128. doi:10.1086/597791

Papachristos, A. V., Wildeman, C., \& Roberto, E. (2015). Tragic, but not random: The social contagion of nonfatal gunshot injuries. Social science \& medicine, 125(1), 139-150. doi:10.1016/j.socscimed.2014.01.056

Rennison, C. M. (2007). Reporting to the police by Hispanic victims of violence. Violence and Victims, 22(6), 754-772. doi:10.1891/088667007782793110

Rosenfeld, R., Bray, T. M., \& Egley, A. (1999). Facilitating violence: A comparison of gangmotivated, gang-affiliated, and nongang youth homicides. Journal of Quantitative Criminology, 15(4), 495-516. doi:10.1023/a:1007548309620

Rosenfeld, R., Gaston, S., Spivak, H., \& Irazola, S. (2017). Assessing and responding to the recent homicide rise in the United States. Washington, DC: U.S. Department of Justice, National Institute of Justice.

Saldana, J. (2009). The coding manual for qualitative researchers. London: Sage Publications.

Sampson, R. J., \& Bartusch, D. J. (1998). Legal cynicism and (subcultural?) tolerance of deviance: The neighborhood context of racial differences. Law and Society Review, 32(4), 777-804. doi:10.2307/827739

Sampson, R. J., Raudenbush, S. W., \& Earls, F. (1997). Neighborhoods and violent crime: A multilevel study of collective efficacy. Science, 277(5328), 918-924. doi:10.1126/science.277.5328.918

Skolnick, J. (1994). Justice without trial: Law enforcement in democratic society (3rd ed.). New York, NY: McMillan. 
Smith, P. E., \& Hawkins, R. O. (1973). Victimization, types of citizen-police contacts, and attitudes toward the police. Law \& Society Review, 8(1), 135-152. doi:10.2307/3052811

Smith, W. R., Frazee, S. G., \& Davison, E. L. (2000). Furthering the integration of routine activity and social disorganization theories: Small units of analysis and the study of street robbery as a diffusion process. Criminology, 38(2), 489-524. doi:10.1111/j.17459125.2000.tb00897.x

Spohn, C., \& Tellis, K. (2014). Policing \& prosecuting sexual assault: Inside the criminal justice. Boulder, CO: Lynne Rienner Publishers.

Tita, G., \& Griffiths, E. (2005). Traveling to violence: The Case for a mobility-based spatial typology of homicide. Journal of Research in Crime and Delinquency, 42(3), 275-308. doi: $10.1177 / 0022427804270051$

Truman, J. L., \& Morgan, R. E. (2016). Criminal victimization, 2015. Washington, DC: Bureau of Justice Statistics, Office of Justice Programs, U.S. Department of Justice.

Tyler, T. R., \& Fagan, J. (2008). Legitimacy and cooperation: Why do people help the police fight crime in their communities. Ohio State Journal of Criminal Law, 6, 231-275.

U.S. Census Bureau. (2013). TIGER/line with selected demographic and economic data, 20092013 American Community Survey 5-year estimates. Retrieved from https://www.census.gov/geo/maps-data/data/tiger-data.html

Van Maanen, J. (1978). The asshole. In P. K. Manning \& J. Van Maanen (Eds.), Policing: A view from the street (pp. 221-238). Santa Monica, CA: Goodyear Publishing Company.

White, M. D., Mulvey, P., \& Dario, L. M. (2016). Arrestees' perceptions of the police: Exploring procedural justice, legitimacy, and willingness to cooperate with police across offender types. Criminal Justice and Behavior, 43(3), 343-364. doi:10.1177/0093854815602501 
Wintemute, G. J. (2015). The epidemiology of firearm violence in the twenty-first century United States. Annual review of public health, 36, 5-19. doi:10.1146/annurev-publhealth031914-122535

Xie, M. (2014). Area differences and time trends in crime reporting: Comparing New York with other metropolitan areas. Justice Quarterly, 31(1), 43-73.

doi:10.1080/07418825.2012.742126

Xie, M., \& Lauritsen, J. L. (2012). Racial context and crime reporting: A test of Black's stratification hypothesis. Journal of Quantitative Criminology, 28(2), 265-293. doi:10.1007/s10940-011-9140-z 
${ }^{\mathrm{i}}$ Criminal nonfatal shootings are inherently difficult to count (Huebner \& Hipple, 2018; Hipple \& Magee, 2017). The two most commonly used official crime data sources, the UCR and NIBRS do not define a nonfatal shooting as a crime in and of itself. In both systems, they are considered aggravated assaults (Federal Bureau of Investigation, 2004, 2013b). NIBRS has made it easier to identify incidents where a nonfatal shooting occurs because this system captures up to ten crime occurrences within a single incident (Federal Bureau of Investigation, 2013a). However, nonfatal shootings are grouped with all aggravated assaults. UCR, on the other hand, designates one crime occurrence per incident, applying the Hierarchy Rule that specifies that an incident is counted as one and only one crime-the most serious crime that occurred during the incident. Therefore, if someone is shot during a robbery incident, the nonfatal shooting or aggravated assault is "lost" and the incident is counted for UCR purposes as the more severe robbery (Federal Bureau of Investigation, 2004).

${ }^{\text {ii }}$ For reference, there were 1,844 official UCR Aggravated Assaults with a Firearm in 2014 and 2,092 in 2015 . However, cases for this study were drawn from the records management system and had not been officially screened for UCR. Using random digits, researchers sampled 614 cases from 2014 and 632 cases from 2015 (approximately one-third for each year) labelled aggravated assault with a firearm. From those, 236 and 167 cases (2014 and 2015 respectively) met our nonfatal shooting definition and were included in this study.

iii St. Louis was added to the project mid-way through the grant period (see Hipple et al. 2017). Time and resources did not allow for a survey of all incidents where an aggravated assault could have occurred. The sample is representative of the total population of nonfatal shootings. Descriptive analysis suggests that the sampled cases are not meaningfully or statistically 
different from the total population in terms of characteristics of the victim, location, and incident characteristics. Results from the current analysis also suggests that the ratio of fatal to nonfatal assaults mirrors the results found in Indianapolis. The sample includes approximately $1 / 3$ of all aggravated assaults; therefore, we estimate that there would be 1,209 nonfatal shootings for the two-year period, and there were 323 gun homicides for the same two-year period. The ratio is roughly four nonfatal shootings to one gun homicide.

${ }^{\text {iv }}$ Researchers disagreed about $8 \%$ of the time on the original cooperation codes. Because final codes were reached by consensus, we did not calculate a Cohen’s Kappa.

${ }^{v}$ The dataset contained $274(20.1 \%)$ cases where researchers were unable to ascertain cooperation. The majority of these cases occurred in Indianapolis. We do not believe the missingness of this variable is random and it is most likely related to unknown motive. Officers did not have or were not provided adequate information to assess victim cooperation. Therefore, we did not impute and chose to listwise delete these cases, leaving us with a final sample size of 1,091 cases.

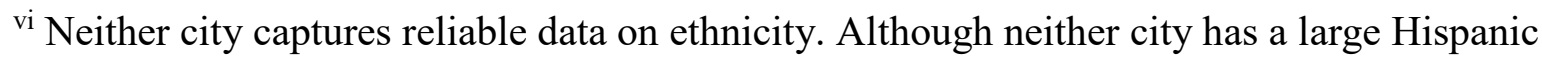
population, there are many cities across the United States where ethnicity may be a central factor. Ethnicity should be the focus of future research.

${ }^{\text {vii }}$ For the Indianapolis incidents, victims who had been previously arrested in Marion County as indicated by a local unique identifier (i.e., Gallery Number) were coded as 1, victims without a Gallery number were coded as $0=$ no previous arrest record. For St. Louis, arrest records were limited to arrests made by the Metropolitan Police Department, City of St. Louis as indicated in the records management system. 
viii The measure of wound location and its severity is limited to data collected by police officers. While the 1990 AIS is not the most recent or detailed wound severity scale, it was the most appropriate for our data. It is possible that a leg wound where the femoral artery is pierced by a bullet was coded as a less severe wound (i.e. extremity) even through it could be life threatening. We were not privy to medical records that would provide the detail needed for such coding, but future research should continue to explore this line of work.

ix Motives coded as "Other" and "Unknown" were collapsed into one category. "Other" motives included money (i.e., not related to any other motive category), unintended or incorrect target, and accidental/self-inflicted and comprised $4.3 \%(n=59)$ of all cases. Any cases where the motive could not be determined $53.8 \%(n=735)$ from the data source were coded as "Unknown." In the case of accidental/ self-inflicted, these were situations where the victim did not admit to shooting himself or herself, but in the opinion of medical personnel and/or police personnel, an accidental or self-inflicted wound seemed the most likely scenario. These cases remained in the sample because they met the definition of an aggravated assault as reported by the victim. That is, unless there was an eyewitness or other irrefutable evidence to contradict the reported assault, the police department reported it as an assault.

${ }^{x}$ Following factor analyses, we use STATA's predict post-estimation command to generate a weighted sum variable of concentrated poverty.

${ }^{x i}$ To examine the robustness of effects across place, and to ensure that reporting differences by place did not influence the main relationships of interest, we tested the model for Indianapolis and St. Louis separately. We found that the patterns demonstrated in our full models held for Indianapolis, but small cell-size in the St. Louis model resulted in complete separation (perfect 
prediction) - making independent analyses by city untenable. Still, patterns in St. Louis generally coincided with the full model patterns.

${ }^{x i i}$ A likelihood-ratio test indicates that this model specification is significantly more efficient than model three $(\chi 2(1)=6.23, \mathrm{p}=.013)$.

${ }^{\text {xiii }}$ Also included in this group are those cases where the victim does not disclose the motive. Because missing on motive is highly dependent on cooperation, we considered an alternative model with an Unknown/Missing dummy variable to provide a more conservative estimate of the impact of robbery. We also estimated the model with non-missing on motive cases only ( $n=$ 400). Under both specifications, the interaction identified in this model was robust in significance and substantive strength, suggesting that the moderating nature of race is not sensitive to model specification. We present the parsimonious and full-sample model here. 